\title{
Antibiotic Resistance Phenotypes of Enterobacteriaceae Isolated from Household Wastewater in Brazzaville, Republic of Congo
}

\author{
Rachel Moyen*, Tarcisse Baloki Ngoulou, Etienne Nguimbi, Gabriel Ahombo \\ Laboratory of Cellular and Molecular Biology, Sciences and Techniques Faculty, University Marien NGOUABI, \\ Brazzaville, Congo \\ Email: *rmoyen@yahoo.fr
}

How to cite this paper: Moyen, R., Ngoulou, T.B., Nguimbi, E. and Ahombo, G. (2021) Antibiotic Resistance Phenotypes of Enterobacteriaceae Isolated from Household Wastewater in Brazzaville, Republic of Congo. Advances in Microbiology, 11, 27-36.

https://doi.org/10.4236/aim.2021.111003

Received: April 2, 2020

Accepted: January 11, 2021

Published: January 14, 2021

Copyright $\odot 2021$ by author(s) and Scientific Research Publishing Inc. This work is licensed under the Creative Commons Attribution-NonCommercial International License (CC BY-NC 4.0). http://creativecommons.org/licenses/by-nc/4.0/

\begin{abstract}
Household wastewater is a source of pollution and can present health risks when discharged into the environment. Thus, samples of household wastewater from a few neighborhoods in Brazzaville were analyzed for microbiological quality. The various samples were cultured for isolation on solid media using conventional microbiological methods. The bacteria isolated were identified by the Enterobacter System gallery. Sensitivity tests were performed using the standard antibiotic susceptibility test by diffusion on Mueller Hinton medium. At the end of the analysis, 51 Enterobacteriaceae were isolated and identified. They included: 8 (15.68\%) Escherichia coli, 8 (15.68\%) Salmonella spp., 8 (15.68\%) Shigella spp., 8 (15.68\%) Klebsiella spp., 5 (9.80\%) Enterobacter aerogenes, 8 (15.68\%) Enterobacter cloacae, 3 (5.90\%) Arizona spp., $3(5.90 \%)$ Proteus spp. The results obtained show that the bacteria tested showed total resistance to the following antibiotics: amoxicillin, amoxicillin + clavulanic acid, cloxacillin and nalidixic acid. On the other hand, imipenem, cefuroxime, cefotaxime, cefftriazone and kanamycin were the most active antibiotics with low levels of resistance. The low resistance rates observed for imipenem, cefotaxime, cefuroxime and cefftriazone show that these antibiotics can be used for the treatment of infections caused by household wastewater bacteria.
\end{abstract}

\section{Keywords}

Antibiotic Therapy, Enterobacteriaceae, Sewage, Households

\section{Introduction}

After half a century of antibiotic use, the emergence and spread of bacterial re- 
sistance is a critical public health issue [1]. The widespread use of broad-spectrum antibiotics in human medicine to treat infections without diagnosis of the specific pathogen involved and in animal husbandry is considered a major factor in bacterial resistance to antimicrobials [2]. In some regions, poor hygienic conditions may be the main cause [3]. Many of the diseases that affect the world's population are linked in part to inadequate domestic and industrial wastewater disposal. Without treatment, wastewater is a growing danger to human health and the natural environment because of its load of toxic chemicals and pathogenic micro-organisms (bacteria, viruses, parasites...). They are therefore a permanent threat to human and animal health [4]. Among the bacteria, we can mention Enterobacteria, a group of bacteria whose natural habitat is the gastrointestinal tract of many warm-blooded animals, including humans. These bacteria represent commensal germs. However, poor hygienic conditions related to the traditional aspect of household sanitation as well as the lack of environmental sanitation can cause the spread of these bacteria in the community. Consequently, these bacteria can acquire virulence factors and become opportunistic pathogens, capable of causing health problems such as gastroenteritis and extra-intestinal infections (affecting the urinary tract, blood and central nervous system) encountered in hospital and community settings [5]. To remedy infections caused by these bacteria, beta-lactam antibiotics are commonly used as first-line molecules. Unfortunately today, many cases of resistance have been observed during the treatment of infections caused by community bacteria. Thus, the purpose of this work is to evaluate the microbiological profile and antibiotic resistance of Enterobacteria isolated from household wastewater for management of these bacteria.

\section{Materials and Methods}

\subsection{Material}

\subsubsection{Biological Material}

The biological material consisted of different strains of Enterobacteriaceae isolated from household wastewater collected from four districts of Brazzaville (Château d'eau, Diata, Moungali and Poto poto) located respectively in the districts: 1 Makélékélé, 3 Poto-poto and 4 Moungali.

\subsubsection{Laboratory Equipment}

It consisted of the culture media for isolation (Eosine Blue Methylene Agar, SS); for the antibiogram (MH), the Enterobacter System gallery and the antibiotic discs. The following antibiotics were tested: amoxicillin (AX., $25 \mu \mathrm{g}$ ), amoxicillin + clavulanic acid (AMC., 20/10 $\mu$ g), cloxacillin (CX., $5 \mu \mathrm{g}$ ), imipenem (IMP., 10 $\mu \mathrm{g})$, cefalotin (CEF., $30 \mu \mathrm{g}$ ), cefalexidine (CXN., $30 \mu \mathrm{g}$ ), cefuroxime (CXM., 30 $\mu \mathrm{g})$, cefotaxime (CTX., $30 \mu \mathrm{g}$ ), cefotaxime (CTX., $30 \mu \mathrm{g}$ ), cefftriazone (CRO., 30 $\mu \mathrm{g}$ ), ceftazidime (CAZ., $30 \mu \mathrm{g}$ ), kanamycin (KAN., $1 \mathrm{mg}$ ), nalidixic acid (NA., 30 $\mu \mathrm{g})$. 


\subsection{Methods}

\subsubsection{Sampling}

Eight sites were selected, with two sites per neighbourhood (Table 1). A total of four (4) samples were collected per site over a two-month period. A one-week interval was observed between samples. $100 \mathrm{~mL}$ of water from each site was collected with a Pyrex glass vial after flaming the opening and then sent to the laboratory in a cooler. These different sites are wells or collectors of water from household use. Once full, these collectors are emptied and the water is poured into the streets.

\subsubsection{Isolation}

The various water samples were seeded on selective agar media. The following media were used:

- Methylene Blue Eosin Agar (EMB) for the isolation of Enterobacteriaceae;

- SS Agar for the isolation of Salmonella and Shigella genus.

\subsubsection{Strain Identification}

An Enterobacter System gallery comprising several biochemical reactions was used for the identification of Enterobacteriaceae.

\subsubsection{Antibiotic Resistance}

Resistance testing was done using the standard Mueller Hinton diffusion susceptibility testing method [6] [7]. An isolated colony of pure culture is suspended in $5 \mathrm{~mL}$ of sterile physiological water which constitutes the inoculum. Previously cast Petri dishes containing Mueller Hinton medium were inoculated by flooding. Excess inoculum is discarded in the bleach and then the plates are inverted and placed in the oven for 15 minutes. The antibiotic discs are then placed on the inoculated agar and the plates are incubated at $37^{\circ} \mathrm{C}$ for 18 to 24 hours. After 18 to 24 hours of incubation, the diffusion diameters of the different antibiotics were measured and compared to the reference diameters of the Antibiogram Committee of the French Society of Microbiology [8].

\subsubsection{Determination of Resistance Phenotypes}

They have been determined by reading the antibiogram, which identifies the clinical types (sensitive, resistant and intermediate). The resistance phenotype is the group of antibiotics to which the strain is resistant.

\section{Results}

\subsection{Isolation and Identification of Strains}

A total of 51 strains of Enterobacteriaceae were isolated. After identification, the strains of Enterobacteriaceae were as shown in Figure 1.

\subsection{Antibiotic Resistance}

The different antibiotic resistance results are shown in Table 2 and Table 3. 


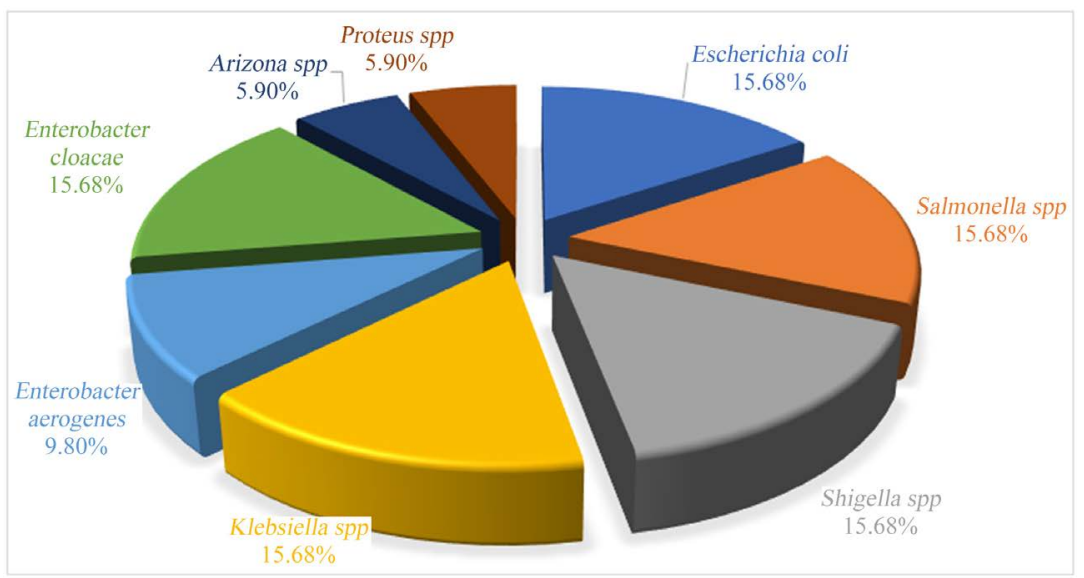

Figure 1. Distribution by identified species.

Table 1. Description of the different sampling sites.

\begin{tabular}{|c|c|c|c|}
\hline Collection sites & Boroughs & Neighbourhoods & Addresses \\
\hline Site 1 & \multirow{2}{*}{1} & \multirow{2}{*}{ Diata } & Fraternity Street No. 17 \\
\hline Site 2 & & & Kimbenza Street No. 52 \\
\hline Site 3 & \multirow{2}{*}{1} & \multirow{2}{*}{ Château d'eau } & Massamba Bernard Street No. 10 \\
\hline Site 4 & & & Saint Paul Street No. 13 \\
\hline Site 5 & \multirow{2}{*}{3} & \multirow{2}{*}{ Poto-poto } & Zandé Streek No. 16 \\
\hline Site 6 & & & Bakoukouyas Street No. 14 \\
\hline Site 7 & \multirow{2}{*}{4} & \multirow{2}{*}{ Moungali } & Djambala Street No. 10 \\
\hline Site 8 & & & Makotipoko Street No. 21 \\
\hline
\end{tabular}

Table 2. Resistance rates of 8 Escherichia coli, Salmonella spp., Shigella spp. and 3 Arizona spp.

\begin{tabular}{|c|c|c|c|c|c|c|c|c|c|c|c|c|c|}
\hline & \multirow{2}{*}{$\begin{array}{c}\text { ATB } \\
\text { tested }\end{array}$} & \multicolumn{3}{|c|}{ Escherichia coli $(\mathrm{n}=8)$} & \multicolumn{3}{|c|}{ Salmonella spp. $(\mathrm{n}=8)$} & \multicolumn{3}{|c|}{ Shigella spp. $(\mathrm{n}=8)$} & \multicolumn{3}{|c|}{ Arizona spp. $(\mathrm{n}=3)$} \\
\hline & & $\mathrm{R}(\%)$ & I (\%) & S (\%) & $\mathrm{R}(\%)$ & I (\%) & S (\%) & R (\%) & I (\%) & S (\%) & $\mathrm{R}(\%)$ & I (\%) & S (\%) \\
\hline & $\mathrm{AX}$ & $8(100)$ & 0 & 0 & $8(100)$ & 0 & 0 & $8(100)$ & 0 & 0 & $3(100)$ & 0 & 0 \\
\hline & $\mathrm{AMC}$ & $8(100)$ & 0 & 0 & $8(100)$ & 0 & 0 & $8(100)$ & 0 & 0 & $3(100)$ & 0 & 0 \\
\hline & $\mathrm{CX}$ & $7(87.5)$ & 0 & $1(12.5)$ & $8(100)$ & 0 & 0 & $8(100)$ & 0 & 0 & $3(100)$ & 0 & 0 \\
\hline \multirow{7}{*}{ Families } & IMP & $1(12.5)$ & 0 & $7(87.5)$ & $4(50)$ & $1(12.5)$ & $3(37.5)$ & $2(25)$ & 0 & $6(75)$ & $1(33.33)$ & $1(33.33)$ & $1(33.34)$ \\
\hline & CEF & $8(100)$ & 0 & 0 & $5(62.5)$ & $3(37.5)$ & 0 & $5(62.5)$ & 0 & $3(37.5)$ & $2(66.67)$ & 0 & $1(33.33)$ \\
\hline & $\mathrm{CXN}$ & $8(100)$ & 0 & 0 & $5(62.5)$ & $3(37.5)$ & 0 & $5(62.5)$ & 0 & $3(37.5)$ & $2(66.67)$ & 0 & $1(33.33)$ \\
\hline & CAZ & $8(100)$ & 0 & 0 & $8(100)$ & 0 & 0 & $8(100)$ & 0 & 0 & $3(100)$ & 0 & 0 \\
\hline & $\mathrm{CXM}$ & $2(25)$ & 0 & $6(75)$ & $8(100)$ & 0 & 0 & $8(100)$ & 0 & 0 & $2(66.67)$ & 0 & $1(33.33)$ \\
\hline & CTX & 0 & 0 & $8(100)$ & $2(25)$ & 0 & $6(75)$ & $2(25)$ & $2(25)$ & $4(50)$ & 0 & 0 & $3(100)$ \\
\hline & CRO & 0 & 0 & $8(100)$ & $2(25)$ & 0 & $6(75)$ & $2(25)$ & 0 & $6(75)$ & 0 & 0 & $3(100)$ \\
\hline \multicolumn{2}{|c|}{ Global resistance } & $50(62.5)$ & 0 & $30(37.5)$ & $58(72.5)$ & $7(8.75)$ & $15(18.75)$ & $56(72)$ & $2(2.5)$ & $22(25.5)$ & $19(63.33)$ & $1(3.33)$ & $10(33.34)$ \\
\hline Aminosides & KAN & 0 & 0 & $8(100)$ & 0 & 0 & $8(100)$ & 0 & 0 & $8(100)$ & 0 & 0 & $3(100)$ \\
\hline \multicolumn{2}{|c|}{ Global resistance } & 0 & 0 & $8(100)$ & 0 & 0 & $8(100)$ & 0 & 0 & $8(100)$ & 0 & 0 & $3(100)$ \\
\hline Quinolones & NA & $8(100)$ & 0 & 0 & $8(100)$ & 0 & 0 & $8(100)$ & 0 & 0 & $3(100)$ & 0 & 0 \\
\hline \multicolumn{2}{|c|}{ Global resistance } & $8(100)$ & 0 & 0 & $8(100)$ & 0 & 0 & $8(100)$ & 0 & 0 & $3(100)$ & 0 & 0 \\
\hline
\end{tabular}

R: Resistance; I: Intermediate; S: Sensitive; \%: Percentage; n: Number; ATB: Antibiotics. Amoxicillin (AX), amoxicillin + Clavulanic Acid (AMC), cloxacillin (CX), imipenem (IMP), cefalotin (CEF), cefalexidine (CXN), cefuroxime (CXM), cefotaxime (CTX), ceftazidime (CAZ), kanamycin (KAN), nalidixic acid (NA), cefalexidine (CXN), cefuroxime (CXM), cefotaxime (CTX), ceftriazone (CRO), ceftazidime (CAZ), kanamycin (KAN), nalidixic acid (NA). 
Table 3. Resistance rates of 8 Klebsiella spp., Enterobacter aerogenes, 8 Enterobacter cloacae and 3 Proteus spp.

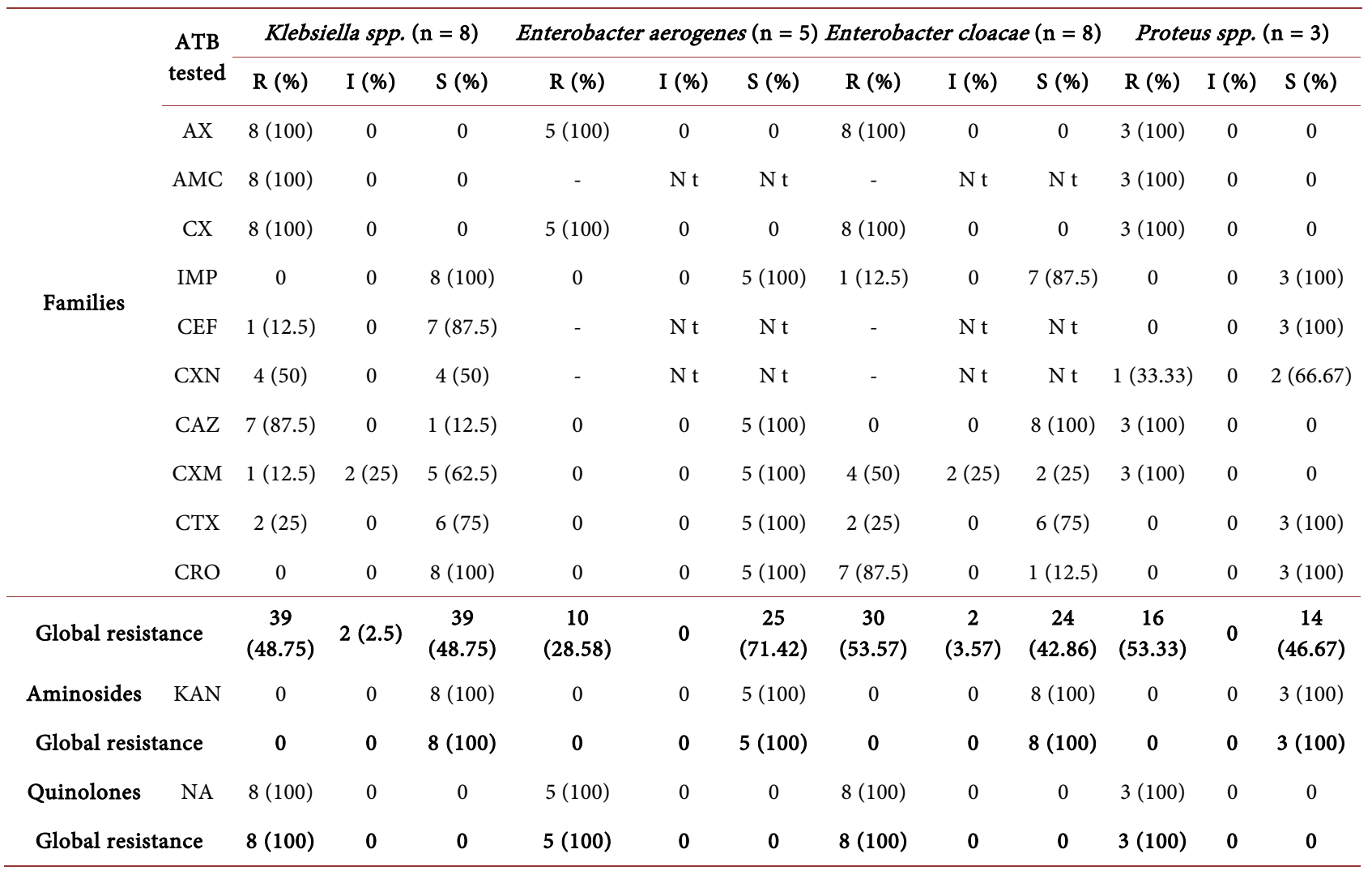

R: Resistance; I: Intermediate; S: Sensitive; \%: Percentage; n: Number; ATB: Antibiotics; -: Natural resistance; N t: Not tested. Amoxicillin (AX), amoxicillin + Clavulanic Acid (AMC), cloxacillin (CX), imipenem (IMP), cefalotin (CEF), cefalexidine (CXN), cefuroxime (CXM), cefotaxime (CTX), ceftazidime (CAZ), kanamycin (KAN), nalidixic acid (NA), cefalexidine (CXN), cefuroxime (CXM), cefotaxime (CTX), ceftriazone (CRO), ceftazidime (CAZ), kanamycin (KAN), nalidixic acid (NA).

Figure 2 shows the distribution of resistance among the different strains of Enterobacteriaceae. This figure shows that Enterobacteriaceae have shown high levels of resistance to ampicillin, amoxicillin, amoxicillin + clavulanic acid, cloxacillin, ceftazidme and nalidixic acid. However, imipenem, cefuroxime, cefotaxime, ceftriazone and kanamycin were more active.

All strains of Enterobacteriaceae have been tested with three families of antibiotics. Of all the families tested, the aminoglycosides (Kanamycin) retained their activity on all strains of Enterobacteriaceae with zero resistance. On the other hand, total resistance was observed for the quinolone family (nalidixic acid). The frequencies ranged from $28.58 \%$ to $72.5 \%$ respectively for Enterobacter aerogenes and Salmonella spp. to beta-lactam resistance (Figure 3).

\subsection{Resistance Phenotype}

The phenotypic resistance patterns observed in Enterobacteriaceae were as follows: 5 strains presented the AX AMC CX CEF CXN CAZ CXM CTX CRO phenotype (15.6\%); 4 strains presented the AX AMC CX IMP CEF CXN CAZ phenotype (12.5\%); 19 strains presented the AX AMC CX CEF CAZ phenotype (59.37\%); 3 strains presented the AX AMC CX CEF CXN CAZ CTX phenotype 
(9.38\%) and 1 strain presented the AX AMC CX CEF CAZ CXM CRO (3.15\%). The presence of these resistance phenotypes in Enterobacteriaceae underscores the inactivation of beta-lactam antibiotics by extended-spectrum beta-lactamases (Figure 4).

\section{Discussion}

This study assessed the antibiotic resistance of Enterobacteriaceae isolated from household wastewater in four neighbourhoods of the city of Brazzaville to antibiotics used in the treatment of Enterobacteriaceae infections.

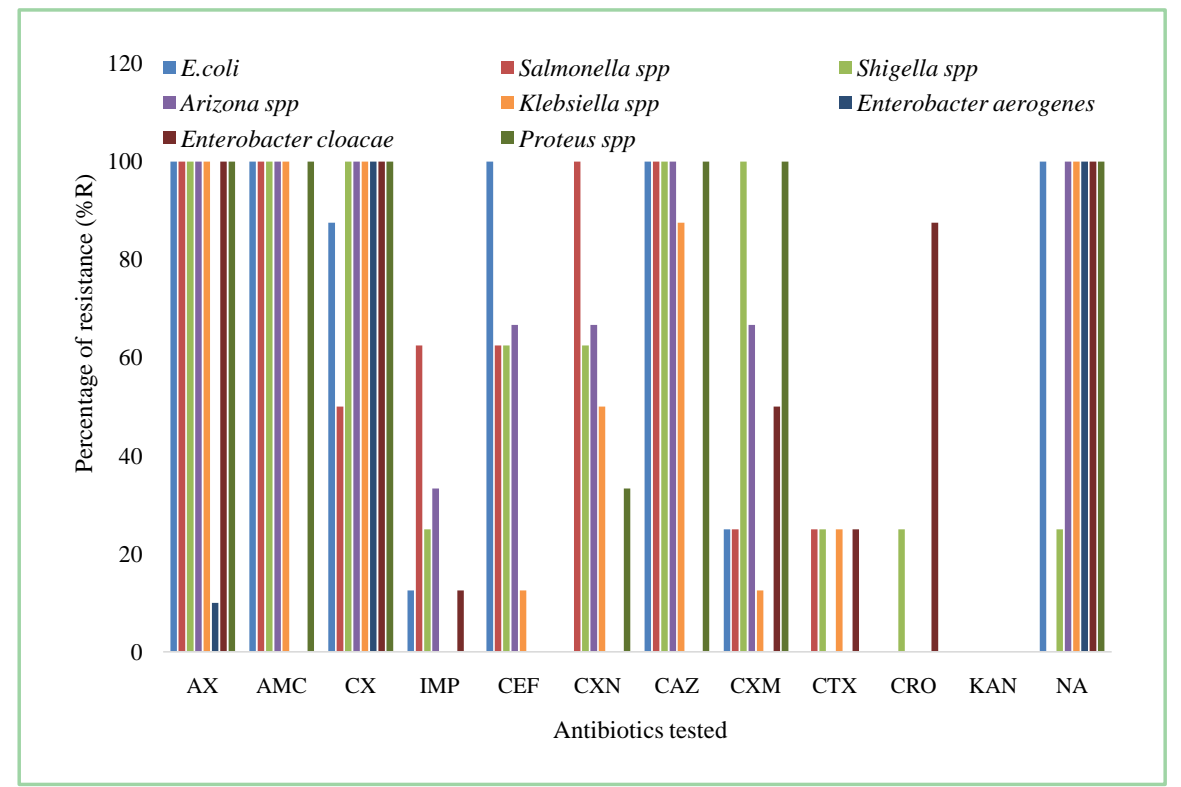

Figure 2. Enterobacteriaceae resistance profile.

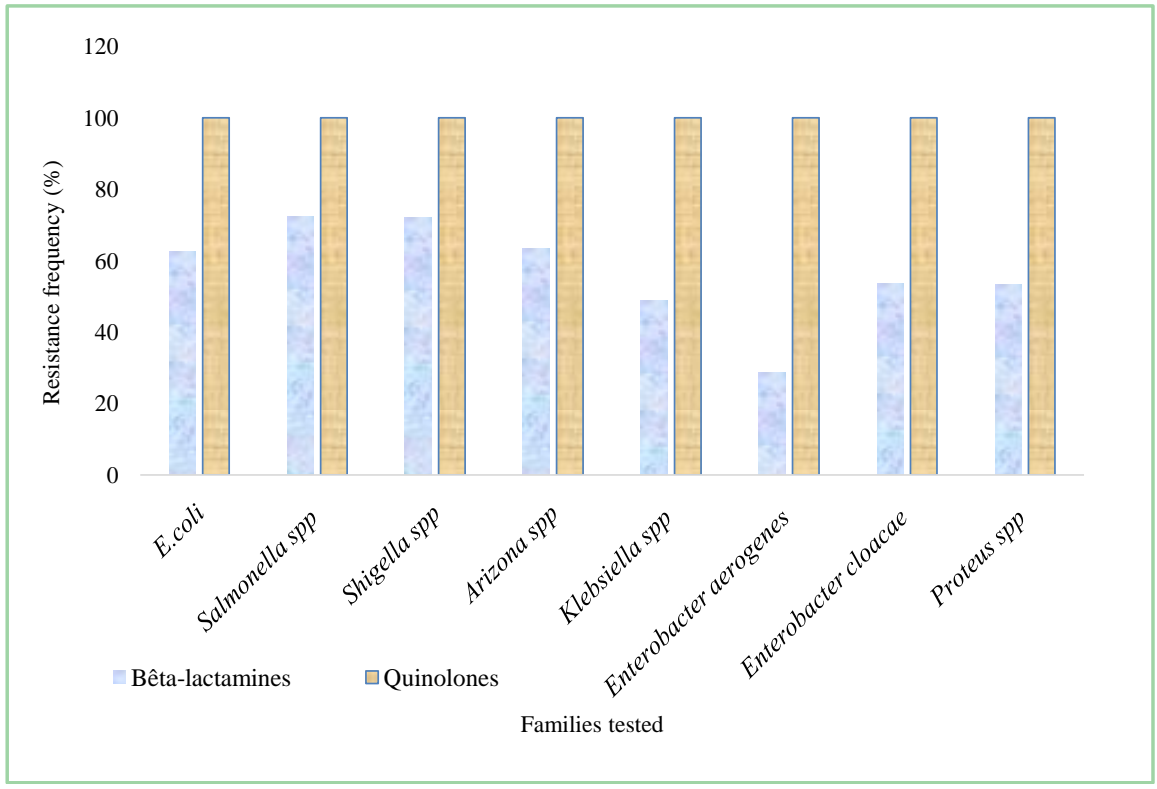

Figure 3. Frequency of resistance by family as a function of species. 


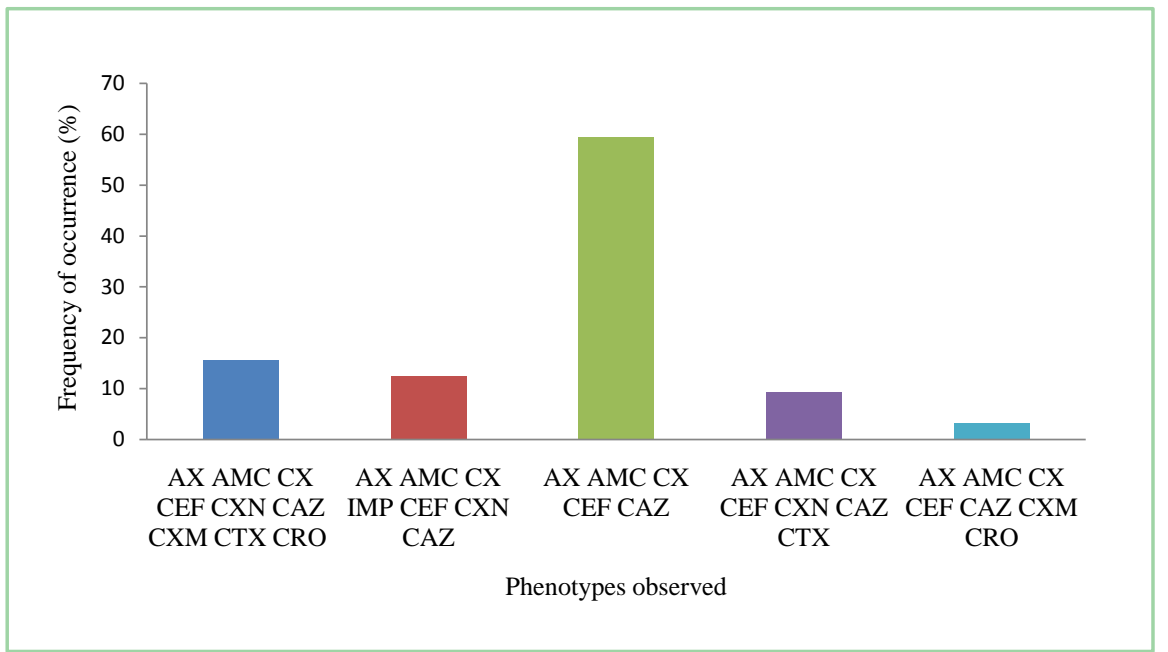

Figure 4. Resistance phenotypes observed in Enterobacteriaceae.

This study revealed resistance rates in E. coli of $100 \%$ for amoxicillin/clavulanic acid and cefalotin. Lower rates were reported in a similar study conducted by Servais et al. [9] in Belgium on E. coli strains isolated from the waters of the Seine basin. In fact, 662 E. coli strains showed resistance rates of $18.6 \%, 17.4 \%$ to amoxicillin/clavulanic acid and cefalotin, respectively [9]. In Morocco, Tagajdid et al. [10] working on E. coli strains isolated from consulting patients in the laboratory of the Cheikh Zayd University Hospital in Rabat reported a 10\% resistance rate to amoxicillin/clavulanic acid. In contrast, Mpelle et al. [11] reported similar resistance rates (100\%) for amoxicillin, amoxicillin + clavulanic acid, and cefalotin each on $E$. coli strains isolated at the Brazzaville Hospital and University Centre. We reported $100 \%$ resistance rates in E. coli to amoxicillin, amoxicillin + clavulanic acid, cefalotin, ceftazidime and nalidixic acid. Lower percentages of resistance were reported by Passerat et al. [12] 25\%, 15\%, 20\%, 0\% and $25 \%$ respectively; Moyen et al. [13] reported 100\%, 87\%, 87\% for amoxicillin, amoxicillin acid/clavulanic acid, cefalotin and ceftazidime. In this study, the rates of resistance to ceftriazone and imipenem in E. coli strains were $0 \%$ and $12.5 \%$, respectively. These frequencies are in disagreement with those reported by Mpelle et al. [11] on E. coli, whose respective rates are $79.07 \%$ and $0 \%$, and by Moyen et al. [13] 73.9\% and 4.3\%. Oubrim et al. [14] reported a zero resistance rate for the same antibiotics tested.

Our results on Enterobacter cloacae and Enterobacter aerogenes (100\%) for amoxicillin are comparative to those found by Oubrim et al. [14] (100\%). In this study, resistance rates on Proteus spp. were for amoxicillin (100\%), cefalotin (0\%), cefuroxime $(100 \%)$, cefuroxime $(100 \%)$, ceftriaxone $(0 \%)$, cefotaxime $(0 \%)$, ceftazidime (100\%), kanamycin (0\%), nalidixic acid (100\%). Different rates of resistance were observed by Souna [15] for amoxicillin (70.4\%), amoxicillin/clavulanic acid (55.5\%), cefalotin (51.8\%), cefuroxime (63\%), cefoxitin (29.6\%), ceftriaxone (25.9\%), cefotaxime (33.3\%), ceftazidine (37\%), kanamycin (33.3\%), for nalidixic acid (33.3\%) and imipenem (11.1\%). Moyen et al. [13] reported resistance rates 
of 91\%; 86.5\%; 41\%; 91\%; 45.5\%; 22.7\% respectively for amoxicillin, cefalotin, cefuroxime, cefuroxime, cefftriazone, cefotaxime, ceftazidime. Our results on Enterobacter cloacae are compared to those found by Souna [15], with respect to amoxicillin (100\%), amoxicillin/clavulanic acid (100\%) whose respective percentages are $100 \%$ each. The frequency of resistance in Enterobacteriaceae (0\%) for kanamycin differs from that found by Souna [15] for kanamycin (17.2\%). The result on Shigella spp. to nalidixic acid (100\%) is compared to that found by Kasolo [16] for 18 strains tested with nalidixic acid (100\%). During our study, our results on nalidixic acid for E. coli (100\%) and Klebsiella spp. (100\%) strains differed from those found by Efuntoye et al. [17] with the respective percentages of $25.7 \%$ and $37 \%$. The high resistance rates could be explained by either diffusion of the clinical strains in the city or transfer of resistance genes from the clinical strains to the community strains. The phenotypes that emerged for amoxicillin and amoxicillin/clavulanic acid could be due to the production of a penicillinbinding protein [18] or to beta-lactamases (cephalosporinases) [19].

In this study, the resistance rates of Escherichia coli, Proteus spp and Klebsiella spp. strains to amoxicillin/clavulanic acid, ceftriazone and nalidixic acid were $100 \%, 0 \%$ and $100 \%$ respectively for each species. In France, Pulcini et al. [20] working on strains of Escherichia coli, Proteus spp. and Klebsiella spp. isolated from people living in retirement homes reported resistance rates for amoxicillin/clavulanic acid, ceftriazone and nalidixic acid (18.5\%, 5.5\%, 19.5\%), (13.5\%, $0.2 \%, 25.5 \%)$ and $(12.2 \%, 4.1 \%, 11.4 \%)$ respectively.

Microorganisms present in wastewater or surface water develop long-term antibiotic resistance due to exposure to low concentrations of antibiotics (ng / to mg /l) [21]. Strain resistance to some antibiotics (beta-lactam antibiotics, some cephalosporins) can be explained by the fact that these antibiotics are used in human and veterinary medicine with no limits on their use (they are most commonly prescribed in ambulatory practice) [9] and by the frequency and extent of wastewater flow from hospitals to the community.

\section{Conclusion}

This study allowed us to determine the antibiotic resistance rates of Enterobacteria isolated from household wastewater and to establish the corresponding phenotypes. The results show that the Enterobacteria showed high rates of resistance to amoxicillin, amoxicillin + clavulanic acid, cloxacillin, ceftazidme and nalidixic acid. Imipenem, cefuroxime, cefotaxime, ceftriaxone and kanamycin were more active. Out of ten (10) beta-lactam antibiotics tested, Enterobacteriaceae were resistant to nine (9) antibiotics with five (5) different profiles, the majority of which were attributed to resistance to six (6) antibiotics (AX AMC CX CEF CAZ). The observed phenotypes involve both penicillin and cephalosporin inhibition. These are the predominant penicillinase and cephalosporinase activities. However, some molecules such as imipenem, cefuroxime, cefotaxime, ceftriaxone and kanamycin can be used for the treatment of infections due to these 
bacteria in household wastewater. To overcome the phenomenon of resistance, these molecules should not be used as monotherapy. Therefore, household wastewater should not be discharged directly into the environment without prior treatment.

\section{Conflicts of Interest}

The authors declare no conflicts of interest regarding the publication of this paper.

\section{References}

[1] Neuhauser, M.M., Weinstein, R.A., Rydman, R., Danziger, L.H., Karam, G. and Quinn, J.P. (2003) Antibiotic Resistance among Gram-Negative Bacilli in US Intensive Care Units: Implications for Fluoroquinolone Use. JAMA, 289, 885-888. https://doi.org/10.1001/jama.289.7.885

[2] Jansen, K.U., Knirsch, C. and Anderson, A.S. (2018) The Role of Vaccines in Preventing Bacterial Antimicrobial Resistance. Nature Medicine, 24, 10-19. https://doi.org/10.1038/nm.4465

[3] Johnson, J.R. and Russo, T.A. (2002) Uropathogenic Escherichia coli as Agents of Diverse Non-Urinary Tract Extraintestinal Infections. The Journal of Infectious Diseases, 186, 859-864. https://doi.org/10.1086/342490

[4] Ouali El Lalami, A., Zanibou, A., Bekhti, K., Zerrouq, F. and Marzouk, M. (2014) Microbiological Quality Control of Domestic and Industrial Wastewater from the City of FES in Morocco. Journal of Materials and Environmental Science, 5, 23252332.

[5] Diallo, A.A. (2013) Pathogenic and Antibiotic-Resistant Escherichia coli in Effluents of Human and Animal Origin: Prevalence and Characterization before and after Purification Treatment. Single Thesis, University of Toulouse III, Toulouse, 204 p.

[6] Durmaz, B., Durmaz, R. and Sahin, K. (1997) Methicillin-Resistance among Turkish Isolates of Staphylococcus aureus Strains from Nosocomial and Community Infections and Their Resistance Patterns Using Various Antimicrobial Agents. Journal of Hospital Infection, 37, 325-329. https://doi.org/10.1016/S0195-6701(97)90149-3

[7] Prats, G., Mirelis, B., Llovet, T., Munoz, C., Miro, E. and Navarro, F. (2000) Antibiotic Resistance Trends in Enteropathogenic Bacteria Isolated in 1985-1987 and 1995-1998 in Barcelona. AntimicrobialAgents and Chemotherapy, 44, 1140-1145. https://doi.org/10.1128/AAC.44.5.1140-1145.2000

[8] Carret, G., Cavallo, J.D., Chardon, H., Chidiac, C., Choutet, P., Courvallin, P., Dabernat, H., Drugeon, H., Dubreuil, L., Golstein, F., Jarlier, V., Leclercq, R., Nchanoine, M.H., Philippon, A., Quentin, C., Rouveix, B., Sirot, J. and Soussy, C.J. (2001) Communiqué du comité de l'antibiogramme de la Société Française de Microbiologie. 47 p.

[9] Servais, P. and Passerat, J. (2009) Antimicrobial Resistance of Fecal Bacteria in Waters of the Seine River Basin (France). Science of the Total Environment, 408, 365-372.

[10] Tagajdid, M.R., Boumhil, L., Iken, M., Adnaoui, M. and Benoud, A. (2010) Study of the Resistance of Escherichia coli Strains Isolated in Urine to Third Generation Fluoroquinolones and Cephalosporins. Medicine and Infectious Diseases, 40, 70-73. https://doi.org/10.1016/j.medmal.2008.10.015 
[11] Mpelle, F.L., Ontsira, N.E.N., Kayath, C.A., Nguimbi, E., Moyen, R. and Kobawila, S.C. (2019) First Report of the Types TEM, CTX-M, SHV and OXA-48 of BetaLactamases in Escherichia coli, from Brazzaville, Congo. African Journal of Microbiology Research, 13, 158-167. https://doi.org/10.5897/AJMR2018.9042

[12] Passerat, J., Anzil, A. and Servais, P. (2009) Antibiotic Resistance of Indigenous and Faecal Bacterial Flora in Rivers of the Seine Basin. PIREN-Seine Report 2008.

[13] Moyen, R., Ahombo, G., Nguimbi, E., Niama, R.F., Ontsira, N.E. and Yala, G.C. (2014) Activity of Beta-Lactam Antibiotics and Production of Beta-Lactamases in Bacteria Isolated from Wound Infections in Brazzaville, Congo. African Journal of Microbiology Research, 8, 2290-2294. https://doi.org/10.5897/AJMR12.1663

[14] Oubrim, N., Cohen, N., Hajjami, K., Mohamed, B. and Mustapha, M.E. (2012) Détection des entérocoques fécaux et Escherichia coli résistant aux antibiotiques isolés à partir des eaux brutes épurées et cultures. European Journal of Scientific Research, 68, 453-461.

[15] Souna, D.M. (2011) Epidemiology of Antibiotic Resistance of Enterobacteria at the C.H.U. of Sidi Bel Abbes. Magisterial Thesis in Biology, Algeria, 148.

[16] Kasolo, F., Yahaya, A.A., Ndihokubwayo, J.B., Impouma, B., Oxenford, C.J., Cognat, S. and Kasolo, F. (2013) WHO Regional Office for Africa, Brazzaville, Africa Regional Office: Guide for Establishing Laboratory-Based Antimicrobial Resistance Surveillance, $32 \mathrm{p}$.

[17] Efuntoye, M.O. and Mopelola, O.A. (2010) Status of Contamination and Antibiotic Resistance of Bacteria from Well Water in Ago-Iwoye, Nigeria. Journal of Applied Biosciences, 35, 2244-2250.

[18] Sotto, A., Boever, C.M., Fabbro, P.P., Gouby, A., Sirot, D. and Jourdan, J. (2001) Risk Factors for Antibiotic-Resistant Escherichia coli Isolated from Hospitalized Patients with Urinary Tract Infections: A Prospective Study. Journal of Clinical Microbiology, 39, 438-444. https://doi.org/10.1128/JCM.39.2.438-444.2001

[19] Bedenic, B. (2004) Beta-Lactamases in Laboratory and Their Role in Resistance Part I: Evolution of Bacterial Resistance Mediated by Beta-Lactamases. Lijecnicki Vjesnik, 126, 314-324.

[20] Pulcini, C., Urmes, I.C., Attinsounon, C.A., Fougnot, S. and Thilly, N. (2018) Antibiotic Resistance of Enterobacteriaceae Causing Urinary Tract Infections in Elderly Patients Living in the Community and in the Nursing Home: A Retrospective Observational Study. Journal of Antimicrobial Chemotherapy, 74, 775-781. https://doi.org/10.1093/jac/dky488

[21] Nagulapally, R.S. (2007) Antibiotic Resistance Patterns in Municipal Wastewater Bacteria. A Thesis Submitted in Partial Fulfillment of the Requirements for the Degree. Master of Science, 28, 587-595. 